\title{
Evaluation of neutralizing antibodies produced by papaya mosaic virus nanoparticles fused to the E2EP3 peptide epitope of Chikungunya envelope
}

\author{
Nor Rashid, N. ${ }^{1}$, Teoh, T.C. ${ }^{2}$, Al-Harbi, S.J. ${ }^{3}$, Yusof, R. ${ }^{1}$, Rothan, H.A. ${ }^{*}$ \\ ${ }^{1}$ Department of Molecular Medicine, Faculty of Medicine, and \\ ${ }^{2}$ Bioinformatics Programme, Institute of Biological Sciences, Faculty of Science, University of Malaya, 50603, Kuala Lumpur, Malaysia \\ ${ }^{3}$ Department of Human Anatomy, College of Medicine, University of Babylon, Iraq \\ ${ }^{4}$ Department of Biology, College of Arts and Sciences, Georgia State University, Atlanta, GA, USA \\ *Corresponding author: hrothan@gsu.edu
}

\section{ARTICLE HISTORY}

Received: 4 August 2020

Revised: 2 December 2020

Accepted: 4 December 2020

Published: 25 March 2021

\begin{abstract}
Chikungunya virus (CHIKV) infection is the cause of acute symptoms and chronic symmetrical polyarthritis associated with long-term morbidity and mortality. Currently, there is no available licensed vaccine or particularly useful drug for human use against CHIKV infection. This study was conducted to evaluate the efficacy of antibodies produced by papaya mosaic virus (PapMV) nanoparticles fused to E2EP3 peptide of CHIKV envelope as a recombinant CHIKV vaccine. PapMV, PapMV-C- E2EP3, and E2EP3-N-PapMV were produced in E. coli with an approximate size of 27 to $30 \mathrm{kDa}$. ICR mice (5 to 6 weeks of age) were injected subcutaneously with 25 micrograms of vaccine construct, and ELISA measured the titer of CHIKV specific IgG antibodies. The results showed that both recombinant proteins E2EP3-N-PapMV and PapMVC-E2EP3 were able to induce IgG antibodies production in immunized mice against CHIKV while immunization with recombinant PapMV showed no IgG antibodies induction. The neutralizing activity of the antibodies generated by either E2EP3-N-PapMV or PapMV-C-E2EP3 exhibited similar inhibition to CHIKV replication in Vero cells using the cells based antibody neutralizing assay and analyzed by plaque formation assay. This study showed the effectiveness of nanoparticles vaccine generated by fusing epitope peptide of CHIKV envelope to papaya mosaic virus envelope in inducing a robust immune response in mice against CHIKV. The data showed that levels of neutralizing antibodies correlate with a protective immune response CHIKV replication.
\end{abstract}

Keywords: Chikungunya virus, vaccine, papaya mosaic virus, nanoparticles.

\section{INTRODUCTION}

Chikungunya virus (CHIKV) is a mosquito-borne enveloped alphavirus belong to the family of Togaviridae. CHIKV contains a single-stranded positive-sense RNA genome of approximately $11.8 \mathrm{kbp}$, which is capped and polyadenylated, encoding two open reading frames (ORFs) (Khan et al., 2002). The $5^{\prime}$ ORF is expressed via cap-dependent translation as an ns-P1-3 or ns-P1-4 polyprotein, and it is cleaved by an nsP2 encoded protease. The structural protein ORF is translated into three main structural proteins: the capsid (C), the envelope glycoproteins E2 and E1, and two other proteins of E3 and 6K (Schmaljohn et al., 1996). The envelop polyprotein of E3E26KE1 is then processed in the endoplasmic reticulum. The mature virion contains 240 of E2/E1 heterodimers arranged in 80 trimeric spikes on the surface, which are inserted into the plasma membrane of infected cells after transport through the secretory pathway. The E2 trimeric spikes are essential for budding of new virus particles and host receptor recognition and attachment, while E1 is responsible for cell entry via $\mathrm{pH}$-dependent endocytosis. The capsid protein is cleaved from the structural polyprotein and encapsidates the cytoplasmic viral genomic RNA. Cytoplasmic nucleocapsids containing the genomic RNA and 240 copies of the capsid protein bud from the cells surface to acquire the virion envelope and envelope protein spikes ( $\mathrm{Li}$ et al., 2010; Weaver et al., 2012).

At present, there is no available licensed vaccine or particularly useful drug for human use for any alphavirus. Several pre-clinical CHIKV vaccines were described. Inactivated virus formulation, like a formalin-inactivated alphavirus vaccine, has proved to be immunogenic in humans (Tiwari et al., 2009; Gardner et al., 2010). Live-attenuated CHIKV vaccines are found to be immunogenic, but they have side effects like arthralgia in a human phase II study (Plante et al., 2011; Partidos et al., 2012). Antibodies are required for protection against CHIKV infections, but DNA vaccines have not been able to generate antibody responses in humans (Gardner et al., 2010; Mallilankaraman et al., 2011) effectively. Chimeric virus vaccines, recombinant adenovirus vaccines, 
subunit protein vaccines are other examples of CHIKV vaccines (Gao et al., 2019; Rezza et al., 2019). Papaya mosaic virus represents an efficient vaccine platform and adjuvant for designing and improving innovative flu vaccines (Rioux et al., 2012; Babin et al., 2013). In this study, an 18-amino acid E2EP3 peptide that was derived from CHIKV envelop (Taussig et al., 1983; Kam et al., 2012; Verma et al., 2014) was fused to the Papaya Mosaic virus envelop (PapMV) as a platform for creating vaccine nanoparticles. The recombinant vaccine was able to induce an immune response in mice against CHIKV. The data showed that levels of neutralizing antibodies correlate with a protective immune response, which can accelerate the development accessibility of CHIKV.

\section{MATERIALS AND METHODS}

A clinical isolate of CHIKV recovered from the serum of infected patients (CHIKV isolate, SGEHICHS277108, Accession FJ445510) was used for propagation by a single passage in C6/36 mosquito cells. Vero cells (ATCC CCL-81) were obtained from the American Type Culture Collection (ATCC; Rockville, MD, USA) and cultured in complete Dulbecco's modified Eagle's medium (DMEM) supplemented with $10 \%$ fetal bovine serum (FBS) as growth medium or $2 \%$ FBS as maintenance medium.

Recombinant Papaya virus particles fused with CHIKV peptide epitope E2EP3. Recombinant plasmid construction was carried out as previously described (Rothan et al., 2013, 2014). In brief, protein sequences of PapMV, PapMV-C-E2EP3, and E2EP3-N-PapMV were converted to DNA sequences and optimized based on $E$. coli preferred codons. Oligonucleotides of 60 mer were designed with an overlapping $3^{\prime}$ ends (15 nucleotides) using the Primer3 (version 0.4.0) analysis software. The long oligonucleotides were annealed, and the mixture of the complementary overlapping oligonucleotides was extended and filled-in with dNTP and Klenow DNA polymerase (Invitrogen, USA). The full DNA fragment was cloned downstream of T7 promoter of the E. coli expression vector. The recombinant plasmid DNA was transformed into E. coli BL21, followed by screening and restriction digestion. The recombinant plasmids were isolated, and the purified plasmids were sequenced to verify the correct sequences without mutations. E. coli harboring recombinant vectors were cultured in $1 \mathrm{~L}$ of LB broth medium supplemented with ampicillin and incubated at $37^{\circ} \mathrm{C}$. The bacterial cells were harvested, lysed, and sonicated on the ice after the induction of protein expression by IPTG. Recombinant protein in the supernatant was purified to $90 \%$ purity by a single-step chromatography on $\mathrm{Ni}^{++}$- metal chelate affinity (Qiagen, UK) columns and eluting at $0.5 \mathrm{M}$ imidazole. The eluted protein profile was analyzed using SDS- PAGE, and the peak fractions were pooled (Rothan et al., 2013, 2014, 2015). The purified proteins were concentrated via Vivaspin ${ }^{\circledR} 20$ concentrator tubes (Viva products, Littleton, MA, USA).

In vivo experiments were carried out following the University of Malaya guidelines on the Care and Use of Laboratory Animals following approval of the animal ethics ISB/18/11/2015/RDVM (R) protocols used in the investigation by the Animal Ethics Committee of the University of Malaya. Twelve ICR mice (5-6 weeks of age) were injected subcutaneously with $25 \mu \mathrm{g}$ of PapMV, E2EP3-N-PapMV, and PapMVC-E2EP3 or endotoxin-free PBS (each group 3 mice). Primary immunization was followed by one booster dose given two weeks later. Sera samples were collected on day 28 after the first injection (14 days post the boost injection) and stored at $-20^{\circ} \mathrm{C}$ until analysis.
The titer of CHIKV-specific IgG antibodies was performed by ELISA, as previously described (Wang et al., 2011). In brief, 96-well plates were coated overnight at $4^{\circ} \mathrm{C}$ with $100 \mu \mathrm{l} /$ well of purified CHIKV antigen in PBS. Plates were blocked with $150 \mu \mathrm{l} /$ well of blocking buffer (PBS containing $0.05 \%$ Tween 20 and $5 \% \mathrm{ABS}$ ) for $1 \mathrm{~h}$ at $37^{\circ} \mathrm{C}$. After washing three times with PBS/0.1\% Tween-20, sera were diuted in blocking buffer in rations ranged from 1:100 to $1: 10,000$ and incubated for two $h$ at room temperature. After four times wash, $100 \mu \mathrm{l}$ of HRPconjugated goat anti-mouse IgG was added to detect mouse antibodies bound to virus-coated wells. After washing steps, the reaction mixtures were developed using TMB $(3,3,5,5$ tetramethylbenzidine) substrate (Sigma-Aldrich), and the absorbance was measured at $450 \mathrm{~nm}$.

Neutralizing activity of antibodies was tested in triplicate and analyzed by plaque formation assay in Vero cells. CHIKV was mixed at a multiplicity of infection (MOI) of 5, with either heat-inactivated mice serum (between 1:50 and $1: 10,000$ ) and incubated for $2 \mathrm{~h}$ at $37^{\circ} \mathrm{C}$, with gentle agitation. Virus-antibody mixtures were then added to Vero cells seeded into 6 -well plates and incubated for $2 \mathrm{~h}$ at $37^{\circ} \mathrm{C}$ with gentle shaking every $15 \mathrm{~min}$. The medium was removed, and cells were washed with PBS and a new DMEM medium supplied with $2 \% \mathrm{FBS}$ and incubated for $72 \mathrm{~h}$ at $37^{\circ} \mathrm{C}$. Culture supernatant was collected, and virus titers were determined by plaque formation assay.

Plaque formation assay was carried out as previously described (Rothan et al., 2014, 2015). In brief, A 10-fold serial dilution of culture supernatant of CHIKV infected cells was added to fresh Vero cells grown in 6 -well plates $\left(0.5 \times 10^{6}\right.$ cells) and incubated for $1 \mathrm{~h}$ at $37^{\circ} \mathrm{C}$. The cells were overlaid with DMEM (maintenance medium) containing $0.5 \%$ agarose. Viral plaques were stained with crystal violet dye after 5day of incubation. Virus titers were calculated according to the following formula: Titer (p.f.u./ml) = number of plaques/ volume of the diluted virus added to the well $\times$ dilution factor of the virus used to infect the well in which the plaques were enumerated.

All assays were performed in quadruplicate, and the statistical analyses were performed using GraphPad Prism version 5.01 (GraphPad Software, San Diego, CA). P values $<0.05$ were considered significant. The error bars are expressed as \pm SD.

\section{RESULTS}

In this study, an 18-amino acid peptide (E2EP3 ${ }_{2800-2818}$ ) derived from CHIKV envelope was fused to the Papaya Mosaic virus envelop (PapMV) as a platform for creating vaccine nanoparticles. Five residues extension from $\mathrm{N}$ - and $\mathrm{C}$ - termini of E2EP3 peptide were included to allow formation the natural secondary structure of the peptide. The position of E2EP3 peptide might influence the formation and immunogenicity of the nanoparticles. Thus, the peptide was fused to either $\mathrm{N}$ - or $\mathrm{C}$ - termini of PapMV (Figure $1 \mathrm{~A}$ and $1 \mathrm{~B}$ ). To achieve this aim, three recombinant plasmid constructs were generated to express the Papaya Mosaic virus envelop without insertion (PapMV), with insertion at the $\mathrm{N}$ - terminus (E2EP3-N-PapMV) and with insertion at C- terminus (PapMV-C$E 2 E P 3)$ as presented in Figure $1 \mathrm{~A}$. The recombinant plasmids were transformed into $E$. coli to express three recombinant proteins named PapMV, E2EP3-N-PapMV, and PapMV-C-E2EP3 (Rothan et al., 2013). The recombinant proteins were affinity purified on a $\mathrm{Ni}^{++}$-column via $6 \mathrm{XH}$ is tag. The expected size of these proteins was approximately 27 to $30 \mathrm{kD}$. (Fig. 1C). 
(A)

1)

\begin{tabular}{|l|l|l|}
\hline T7 Promoter & 6X-His Tag & PapMV \\
\hline
\end{tabular}

2)

\begin{tabular}{|l|l|l|l}
\hline T7 Promoter & 6X-His Tag & PapMV & E2EP3
\end{tabular}

3)

\begin{tabular}{|l|l|l|l|}
\hline T7 Promoter & 6X-His Tag & E2EP3 & PapMV \\
\hline
\end{tabular}

(C)

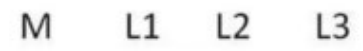

$30 \mathrm{kD}$

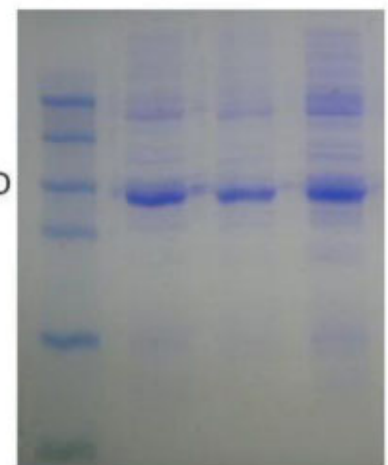

(B)

PapMV

E2EP3-PapMV

PapMV-E2EP3
MASTPNIAFPAITQEQMSSI KVDPTSNLLPSQEQLKSVSTLMVAAKVPAASVTTVALELV NFCYDNGSSAYTTVTGPSSI PE ISLAQLAS IVKASGT SLRKFCRYFAPI IWNLRTDKMAP ANWEASGYKPSAKFAAFDFFDGVENPAAMQPPSGLTRSPTQEERIANATNKQVHLFQAAA QDNNFASNSAFITKGQISGSTPTIQFLPPPETSTRHHHHHH*

MASTPNIA HRQRRSTKDNFNVTKATRPYLAHCPDCGE PAITQEQMSSIKVDPTSNLLPSQ EQLKSVST LMVAAKVPAASVTTVALELVNECY DNGSSAYTTVTGPSSIPEISLAQLAS IV KASGTSLRKFCRYFAPI IWNLRTDKMAPANWEASGYKPSAKFAAFDFFDGVENPAAMQPP SGLTRSPTQEERIANATNKQVHLFQAAAQDNNEASNSAF ITKGQ ISGST PT IQFLPPPET STRHHHHHH*

MASTPNIAFPAITQEQMSSIKVDPTSNLLPSQEQLKSVSTLMVAAKVPAASVTTVALELV NFCYDNGSSAYTTVTGPSSI PE ISLAQLAS IVKASGTSLRKFCRYFAPI IWNLRTDKMAP ANWEASGYKPSAKFAAFDFF DGVENPAAMQPPSGLTRSPTQEERIANATNKQVHLFQAAA QDNNFASNSAFITKGQISGSTPTIQFL PPPET HRQRRSTKDNFNVTKATRPYLAHCPDCG TRHHHHHH*

Figure 1. Design and expression of recombinant CHIKV vaccine nanoparticles.

( $A$ and B) The amino acid sequence of E2EP3 peptide derived from CHIKV envelop was fused to the Papaya Mosaic virus envelop (PapMV) as a platform for creating vaccine nanoparticles. The peptide sequence (bold) was flanked from $\mathrm{N}$ - and $\mathrm{C}$ - termini with five residues extension from CHIKV envelop (italic-underlined) for favor natural processing of the peptide. The peptide was fused either at $\mathrm{N}$ - or $\mathrm{C}$ - terminus resulting in two recombinant proteins PapMV, E2EP3-N-PapMV and PapMV-C- E2EP3 or without insertion PapMV. (C) The recombinant proteins were affinity purified on a $\mathrm{Ni}^{++}$-column via 6XHis tag. The expected size of these proteins was approximately 27 to $30 \mathrm{kD}$ based on SDS-page results, M (marker), L1 (PapMV), L2 (E2EP3 -N-PapMV) and L3 (PapMVC- E2EP3).

In this study, the immune response to PapMV nanoparticles was examined by a subcutaneous injection of twelve mice with $25 \mu \mathrm{g}$ each of the recombinant PapMV, E2EP3N-PapMV, PapMV-C-E2EP3 or endotoxin-free PBS. A booster dose was given on day 15 after primary immunization. Mice sera were assayed for anti- PapMV, E2EP3-N-PapMV, and PapMV-C-E2EP3 antibodies. The results showed both recombinant proteins E2EP3-N-PapMV and PapMV-C-E2EP3 were able to induce IgG antibodies production in immunized mice against CHIKV while immunization with recombinant PapMV or endotoxin-free PBS showed no IgG antibodies induction (Figure 2).

One of the advantages of peptidic vaccination is the good mimicry of the fused epitope. To check if the peptide derived from the CHIKV surface glycoprotein that is fused to the C-terminal or $\mathrm{N}$-terminal of the PapMV can exhibit differences antibodies affinity to CHIKV. The neutralizing activity of antibodies generated by either E2EP3-N-PapMV or PapMV-C-E2EP3 was tested in vitro using the cells-based antibody neutralizing assay and analyzed by plaque formation assay. CHIKV was mixed at a multiplicity of infection (MOI) of 5 , with either heat-inactivated mice serum using increasing dilution factor. The results showed that E2EP3-N-PapMV and PapMV-C-E2EP3 exhibited similar inhibition to CHIKV replication in Vero cells (Figure $3 \mathrm{~A}$ and $3 B)$. Dilutions at $1: 50$ to $1: 200$ of mice sera containing antiCHIKV antibodies were able to reduce virus titters from $7 \times 10^{7}$ to $2 \times 10^{7}$ compare to low reduction in virus titters of the higher dilution factors (Figure $3 \mathrm{~A}$ ).

\section{DISCUSSION}

CHIKV disease is characterized by acute symptoms that generally last about a week and are self-limiting and chronic symmetrical polyarthritis/polyarthralgia lasting for months to years, indicating long-term morbidity and mortality of CHIKV (Gasque et al., 2016; Goupil et al., 2016; Rothan et al., 2016). In recent years, CHIKV disease has become a global public health problem. However, there is no licensed vaccine available for CHIKV. The current study provides a method of producing recombinant CHIKV vaccine nanoparticles.

Our data are supported by recent studies that show that protective antibodies play a role in the control of CHIKV infection. Previous studies show that the neutralization of 


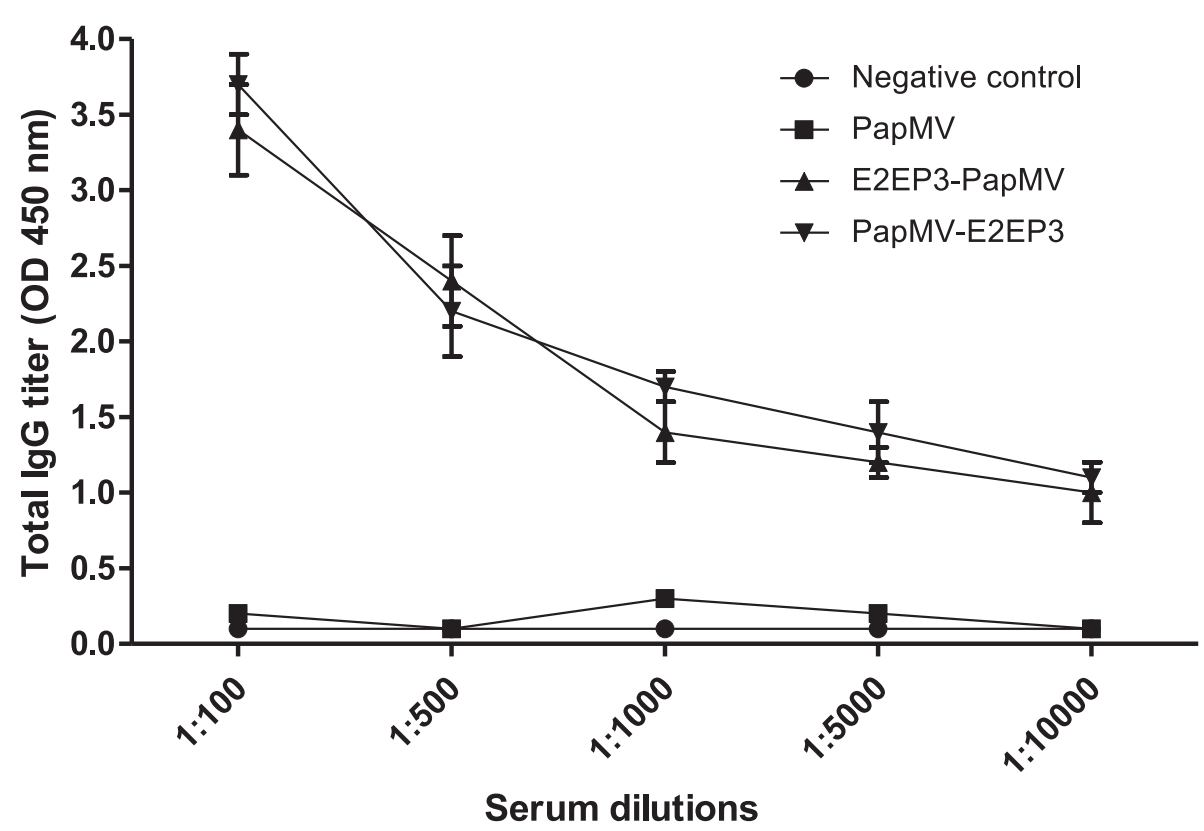

Figure 2. Antibody profiles of PapMV nanoparticles in immunized mice.

Virus-specific IgG antibody titers in each serum sample were determined by ELISA using purified CHIKV virions. Mice were injected subcutaneously with $25 \mu \mathrm{g}$ of PapMV, E2EP3-N-PapMV, and PapMV-C-E2EP3 or endotoxin-free PBS. Primary immunization was followed by one booster dose given 2 weeks later. Sera samples were collected after 28 days after the first injection (14 days post the boost injection) and diluted at 1:100 to $1: 10,000$ in blocking buffer for ELISA assay. The recombinant proteins E2EP3-N-PapMV and PapMV-C-E2EP3 were able to induce IgG antibodies production in immunized mice against CHIKV while immunization with recombinant PapMV or endotoxin-free PBS showed no IgG antibodies induction.
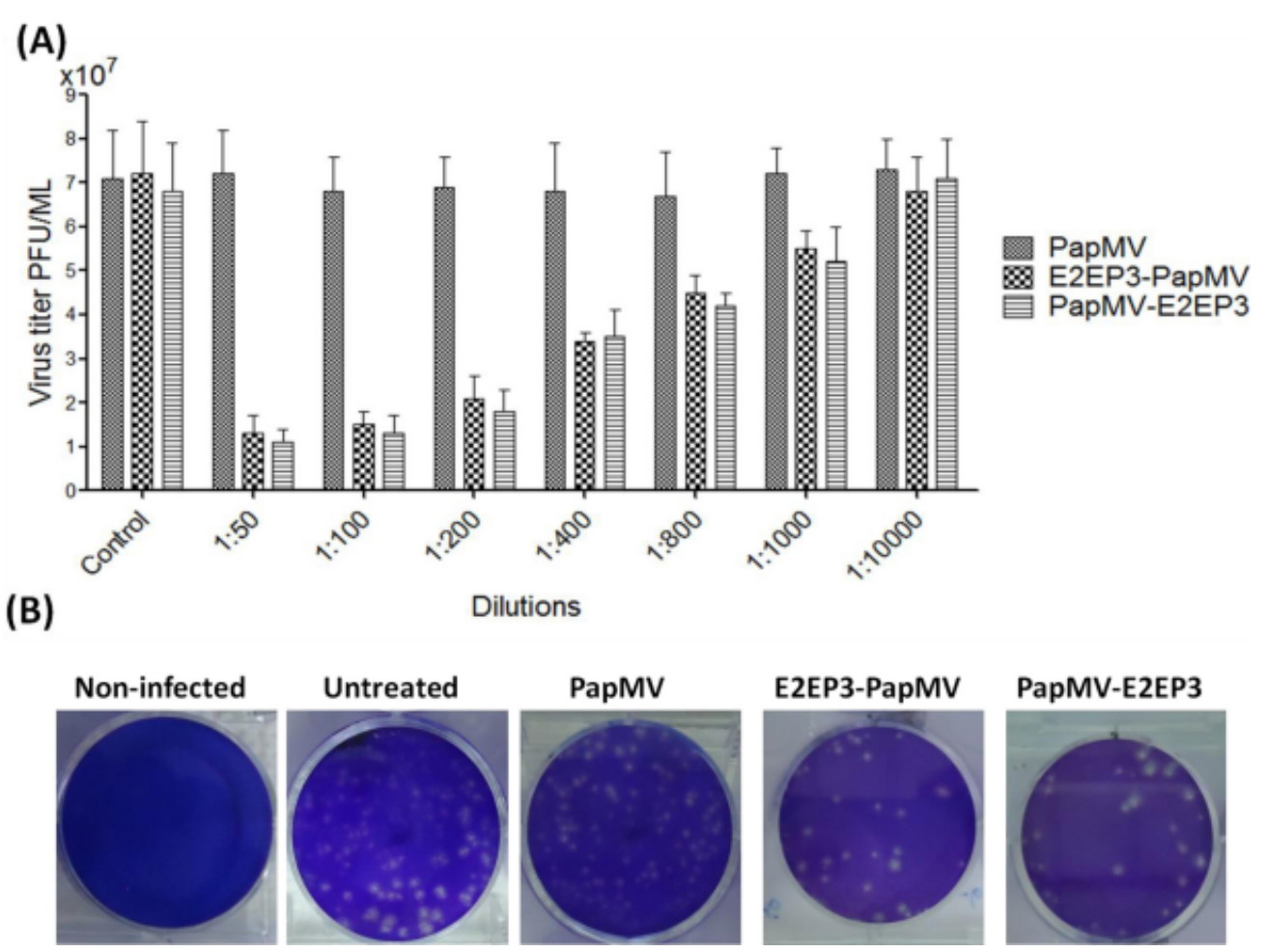

PapMV

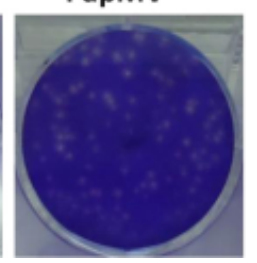

E2EP3-PapMV

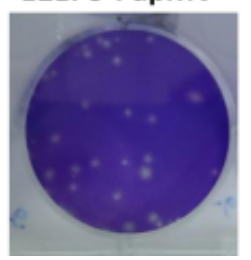

Figure 3. Plaque reduction neutralization assay.

(A) CHIKV was mixed with heat-inactivated mice sera at serial dilutions ranged from 1:50 to 1:10,000. After incubation for $2 \mathrm{~h}$ at $37^{\circ} \mathrm{C}$, virus-antibody mixtures were then added to Vero cells at an MOl of 5 and incubated for $72 \mathrm{~h}$. Culture supernatant was collected and virus titers were determined by plaque formation assay. (B) A serial dilution of culture supernatant of CHIKV infected cells treated with 1:50 dilution was added to fresh Vero cells grown in 6-well plates. The cells were overlaid with DMEM and viral plaques were stained with crystal violet dye after 5-day of incubation. 
viruses by anti-CHIKV antibodies protects against CHIK infection (Weaver et al., 2012; Salazar-Gonzalez et al., 2015). Natural CHIKV infections induce high neutralizing antibody levels from 40 to 20,000 in titter (Lanciotti et al., 2007), which have been detected in CHIKV patients during the infection course. The presence of IgG antibodies correlates with viral clearance and long-term protection (Kam et al., 2012).

It has been known that Virus-like particle (VLP) formulation mimics the native virus surface architecture and protein conformation, and it induces protective antibody responses in the absence of adjuvant (Metz et al., 2011). A recent CHIKV VLP-based vaccine provides protection in both mice and non-human primates by DNA transfection of mammalian cells, but this system out-performs cost and scalability (Couderc et al., 2009; Akahata et al., 2010; Roldao et al., 2010), therefore, the CHIKV VLPs in the presence of adjuvant are economical and easy to scale up for an epidemic response. It has been shown that the E2 domain of the CHIKV envelope glycoprotein, which binds with high affinity to CHIKV, is responsible for virus neutralization. This data shows that levels of neutralizing antibodies correlate with a protective immune response, which can accelerate the development accessibility of the CHIKV vaccine (Weaver et al., 2012). Based on the advantage of nanoparticle vaccine, we sought to test the protection efficiency, and immunogenicity of engineered papaya mosaic virus nanoparticles (PapMV-VLPs) fused with peptide-epitope derived from Chikungunya E2 glycoprotein to trigger a protective immune response against CHIKV. The PapMV platform is rod-shaped $(15 \mathrm{~nm}$ in diameter $\sim 150-250 \mathrm{~nm}$ in length, which was recently shown to induce a high antibody response against a hepatitis C virus (HCV) epitope (Tremblay et al., 2006; Denis et al., 2007).

\section{CONCLUSION}

In conclusion, vaccination is the most cost-effective means of protecting the at-risk populations in CHIK-endemic developing countries. CHIK epidemics are, however, explosive and rapidly moving, but not predictable. This study showed the effectiveness of nanoparticles vaccine generated by fusing epitope peptide of CHIKV envelope to papaya mosaic virus envelop (PapMV). The recombinant vaccine was able to induce an immune response in mice against CHIKV.

\section{ACKNOWLEDGEMENTS}

This study was funded by the Ministry of Higher Education through the Trans Disciplinary Research Grant Scheme (TR001B-2014B).

\section{Conflict of interest}

The authors declare that they have no conflict of interest.

\section{REFERENCES}

Akahata, W., Yang, Z.Y., Andersen, H., Sun, S., Holdaway, H.A., Kong, W.P., Lewis, M.G., Higgs, S., Rossmann, M.G., Rao, S. \& Nabel, G.J. (2010). A virus-like particle vaccine for epidemic Chikungunya virus protects nonhuman primates against infection. Nature medicine 16: 334-338. https:// doi.org/10.1038/nm.2105

Babin, C., Majeau, N. \& Leclerc, D. (2013). Engineering of papaya mosaic virus (PapMV) nanoparticles with a CTL epitope derived from influenza NP. Journal of Nanobiotechnolog 11: 10. https://doi.org/10.1186/1477-3155-1110
Couderc, T., Khandoudi, N., Grandadam, M., Visse, C., Gangneux, N., Bagot, S., Prost J.-F. \& Lecuit, M. (2009). Prophylaxis and therapy for Chikungunya virus infection. The Journal of Infectious Diseases 200: 516-523. https:// doi.org/10.1086/600381

Denis, J., Majeau, N., Acosta-Ramirez, E., Savard, C., Bedard, M.C., Simard, S., Lecours, K., Bolduc, M., Pare, C., Willems, B., Shoukry, N., Tessier, P., Lacasse, P., Lamarre, A., Lapointe, R., Macias, C.L. \& Leclerc, D. (2007). Immunogenicity of papaya mosaic virus-like particles fused to a hepatitis $C$ virus epitope: evidence for the critical function of multimerization. Virology 363: 59-68. https://doi.org/ 10.1016/j.virol.2007.01.011

Gao, S., Song, S. \& Zhang, L. (2019). Recent Progress in Vaccine Development A gainst Chikungunya Virus. Frontiers in Microbiology 10: 2881. https://doi.org/10.3389/fmicb.2019. 02881

Gardner, J., Anraku, I., Le, T.T., Larcher, T., Major, L., Roques, P., Schroder, W.A., Higgs, S. \& Suhrbier, A. (2010). Chikungunya virus arthritis in adult wild-type mice. Journal of Virology 84: 8021-8032. https://doi.org/10.1128/JVI.02603-09

Gasque, P., Bandjee, M.C., Reyes, M.M. \& Viasus, D. (2016). Chikungunya Pathogenesis: From the Clinics to the Bench. The Journal of Infectious Diseases 214: S446-S448. https:// doi.org/10.1093/infdis/jiw362

Goupil, B.A. \& Mores, C.N. (2016). A Review of Chikungunya Virus-induced Arthralgia: Clinical Manifestations, Therapeutics, and Pathogenesis. The Open Rheumatology Journal 10: 129-140. https://doi.org/10.2174/18743129016 10010129

Kam, Y.W., Lum, F.M., Teo, T.H., Lee, W.W., Simarmata, D., Harjanto, S., Chua, C.L., Chan, Y.F., Wee, J.K., Chow, A., Lin, R.T.P., Leo, Y.S., Grand, R.L., Sam, I.C., Tong, J.C., Roques, P., Wiesmuller, K.H., Renia, L., Rotzschke, O. \& Ng, L.F.P. (2012). Early neutralizing IgG response to Chikungunya virus in infected patients targets a dominant linear epitope on the E2 glycoprotein. EMBO Molecular Medicine 4: 330-343. https://doi.org/10.1002/emmm.201200213

Kam, Y.W., Simarmata, D., Chow, A., Her, Z., Teng, T.S., Ong, E.K.S., Renia, L., Leo, Y.S. \& Ng, L.F.P. (2012). Early appearance of neutralizing immunoglobulin $\mathrm{G} 3$ antibodies is associated with chikungunya virus clearance and long-term clinical protection. The Journal of Infectious Diseases 205: 1147-1154. https://doi.org/10.1093/infdis/jis033

Khan, A.H., Morita, K., Parquet, M.d., Mdel, C., Hasebe, F., Mathenge, E.G. \& Igarashi, A. (2002). Complete nucleotide sequence of chikungunya virus and evidence for an internal polyadenylation site. The Journal of General Virology 83: 3075-3084. https://doi.org/10.1099/0022-1317-83-12-3075

Lanciotti, R.S., Kosoy, O.L., Laven, J.J., Panella, A.J., Velez, J.O., Lambert, A.J. \& Campbell, G.L. (2007). Chikungunya virus in US travelers returning from India, 2006. Emerging Infectious Diseases 13: 764-767. https://doi.org/10.3201/ eid1305.070015

Li, L., Jose, J., Xiang, Y., Kuhn, R.J. \& Rossmann, M.G. (2010). Structural changes of envelope proteins during alphavirus fusion. Nature 468: 705-708. https://doi.org/ 10.1038/ nature09546

Mallilankaraman, K., Shedlock, D.J., Bao, H., Kawalekar, O.U., Fagone, P., Ramanathan, A.A., Ferraro, B., Stabenow, J., Vijayachari, P., Sundaram, S.G., Muruganandam, N., Sarangan, G., Srikanth, P., Khan, A.S., Lewis, M.G., Kim, J.J., Sardesai, N.Y., Muthumani, K. \& Weiner, D.B. (2011). A DNA vaccine against chikungunya virus is protective in mice and induces neutralizing antibodies in mice and nonhuman primates. PLoS Neglected Tropical Diseases 5: e928. https://doi.org/10.1371/journal.pntd.0000928 
Metz, S.W. \& Pijlman, G.P. (2011). Arbovirus vaccines; opportunities for the baculovirus-insect cell expression system. Journal of Invertebrate Pathology 107 (Supplement): S16-S30. https://doi.org/10.1016/j.jip.2011.05.002

Partidos, C.D., Paykel, J., Weger, J., Borland, E.M., Powers, A.M., Seymour, R., Weaver, S.C., Stinchcomb, D.T. \& Osorio, J.E. (2012). Cross-protective immunity against o'nyong-nyong virus afforded by a novel recombinant chikungunya vaccine. Vaccine 30: 4638-4643. https://doi.org/10.1016/ j.vaccine.2012.04.099

Plante, K., Wang, E., Partidos, C.D., Weger, J., Gorchakov, R., Tsetsarkin, K., Borland, E.M., Powers, A.M., Seymour, R., Stinchcomb, D.T., Osorio, J.E., Frolov, I. \& Weaver, S.C. (2011). Novel chikungunya vaccine candidate with an IRES-based attenuation and host range alteration mechanism. PLOS Pathogens 7: e1002142. https://doi.org/10.1371/journal. ppat.1002142

Rezza, G. \& Weaver, S.C. (2019). Chikungunya as a paradigm for emerging viral diseases: Evaluating disease impact and hurdles to vaccine development. PLoS Neglected Tropical Diseases 13: e0006919. https://doi.org/10.1371/ journal.pntd.0006919

Rioux, G., Babin, C., Majeau, N. \& Leclerc, D. (2012). Engineering of papaya mosaic virus (PapMV) nanoparticles through fusion of the HA11 peptide to several putative surfaceexposed sites. PloS One 7: e31925. https://doi.org/10.1371/ journal.pone.0031925

Roldao, A., Mellado, M.C., Castilho, L.R., Carrondo, M.J. \& Alves, P.M. (2010). Virus-like particles in vaccine development. Expert Review of Vaccines 9: 1149-1176. https://doi.org/ 10.1586/erv.10.115

Rothan, H.A., Ambikabothy, J., Abdulrahman, A.Y., Bahrani, H., Golpich, M., Amini, E., Rahman, N.A., Teoh, T.C., Mohamed, Z. \& Yusof, R. (2015). Scalable Production of Recombinant Membrane Active Peptides and Its Potential as a Complementary Adjunct to Conventional Chemotherapeutics. PloS One 10: e0139248. https://doi.org/10.1371/journal. pone. 0139248

Rothan, H.A., Bahrani, H., Abdulrahman, A.Y., Mohamed, Z., Teoh, T.C., Othman, S., Rashid, N.N., Rahman, N.A. \& Yusof, R. (2016). Mefenamic acid in combination with ribavirin shows significant effects in reducing chikungunya virus infection in vitro and in vivo. Antiviral Research 127: 50-56. https://doi.org/10.1016/j.antiviral.2016.01.006

Rothan, H.A., Bahrani, H., Mohamed, Z., Abd, Rahman, N. \& Yusof, R. (2014). Fusion of protegrin-1 and plectasin to MAP30 shows significant inhibition activity against dengue virus replication. PloS One 9: e94561. https:// doi.org/10.1371/journal.pone.0094561

Rothan, H.A., Bahrani, H., Mohamed, Z., Teoh, T.C., Shankar, E.M., Rahman, N.A. \& Yusof, R. (2015). A combination of doxycycline and ribavirin alleviated chikungunya infection. PloS One 10: e0126360. https://doi.org/10.1371/ journal.pone. 0126360

Rothan, H.A., Bahrani, H., Rahman, N.A. \& Yusof, R. (2014). Identification of natural antimicrobial agents to treat dengue infection: In vitro analysis of latarcin peptide activity against dengue virus. BMC Microbiology 14: 140. https://doi.org/10.1186/1471-2180-14-140

Rothan, H.A., Bahrani, H., Shankar, E.M., Rahman, N.A. \& Yusof, R. (2014). Inhibitory effects of a peptide-fusion protein (Latarcin-PAP1-Thanatin) against chikungunya virus. Antiviral Research 108: 173-180. https://doi.org/10.1016/ j.antiviral.2014.05.019
Rothan, H.A., Mohamed, Z., Paydar, M., Rahman, N.A. \& Yusof, R. (2014). Inhibitory effect of doxycycline against dengue virus replication in vitro. Archives of Virology 159: 711-718. https://doi.org/10.1007/s00705-013-1880-7

Rothan, H.A., Mohamed, Z., Suhaeb, A.M., Rahman, N.A. \& Yusof, R. (2013). Antiviral cationic peptides as a strategy for innovation in global health therapeutics for dengue virus: high yield production of the biologically active recombinant plectasin peptide. Omics: A Journal of Integrative Biology 17: 560-567. https://doi.org/10.1089/ omi.2013.0056

Rothan, H.A., Suhaeb, A.M. \& Kamarul, T. (2013). Recombinant human adiponectin as a potential protein for treating diabetic tendinopathy promotes tenocyte progenitor cells proliferation and tenogenic differentiation in vitro. International Journal of Medical Sciences 10: 1899-1906. https://doi.org/10.7150/ijms.6774

Salazar-Gonzalez, J.A., Angulo, C. \& Rosales-Mendoza, S. (2015). Chikungunya virus vaccines: Current strategies and prospects for developing plant-made vaccines. Vaccine 33: 3650-3658. https://doi.org/10.1016/j.vaccine.2015.05.104

Schmaljohn, A.L. \& McClain, D. (1996). Alphaviruses (Togaviridae) and Flaviviruses (Flaviviridae). In: th, Baron $S$, editors. Medical Microbiology. Galveston (TX).

Taussig, M.J. \& Holliman, A. (1983). Immunological activity of a T-hybrid line. II. Mapping H-2 genes for the SRBC-specific suppressor factor, its acceptor, and suppression of the antibody response. Hybridoma 2: 311-319. https://doi.org/ 10.1089/hyb.1983.2.311

Tiwari, M., Parida, M., Santhosh, S.R., Khan, M., Dash, P.K. \& Rao, P.V. (2009). Assessment of immunogenic potential of Vero adapted formalin inactivated vaccine derived from novel ECSA genotype of Chikungunya virus. Vaccine 27: 25132522. https://doi.org/10.1016/j.vaccine.2009.02.062

Tremblay, M.H., Majeau, N., Gagne, M.E., Lecours, K., Morin, H., Duvignaud, J.B., Bolduc, M., Chouinard, N., Pare, C., Gagne, S. \& Leclerc, D. (2006). Effect of mutations K97A and E128A on RNA binding and self assembly of papaya mosaic potexvirus coat protein. The FEBS Journal 273: 1425. https://doi.org/10.1111/j.1742-4658.2005.05033.x

Verma, P., Bhatnagar, S., Kumar, P., Chattree, V., Parida, M.M., Hoti, S.L., Shakir, A. \& Rao, D.N. (2014). Analysis of antibody response (IgM, IgG, IgG3) to Chikungunya virus using panel of peptides derived from envelope protein for serodiagnosis. Clinical Chemistry and Laboratory Medicine 52: 297-307.

Wang, D., Suhrbier, A., Penn-Nicholson, A., Woraratanadharm, J., Gardner, J., Luo, M., Le, T.T., Anraku, I., Sakalian, M., Einfeld, D. \& Dong, J.Y. (2011). A complex adenovirus vaccine against chikungunya virus provides complete protection against viraemia and arthritis. Vaccine 29: 2803-2909. https://doi.org/10.1016/j.vaccine.2011.01.108

Weaver, S.C., Osorio, J.E., Livengood, J.A., Chen, R. \& Stinchcomb, D.T. (2012). Chikungunya virus and prospects for a vaccine. Expert Review of Vaccines 11: 1087-1101. https://doi.org/ 10.1586/erv.12.84 